\title{
ЗЕМЛЕУСТРОЙСТВО В БОЛГАРИИ
}

\section{Елизавета Владиславовна Гниненко}

Московский государственный университет геодезии и картографии, 105064, Россия, г. Москва, Гороховский переулок, 4, обучающийся, тел. (915)101-00-62, e-mail: lebensladge11@gmail.com

\section{Александр Павлович Сизов}

Московский государственный университет геодезии и картографии, 105064, Россия, г. Москва, Гороховский переулок, 4 , доктор технических наук, зав. кафедрой кадастра и основ земельного права, тел. (906)716-27-10, e-mail: ap_sizov@mail.ru

В данной статье рассмотрена система землеустройства в Болгарии, климатические особенности и рельеф страны, полезные ископаемые, растительный мир, экономика, земельные ресурсы и правовые нормы управления земельными ресурсами, Аналоги российских документов территориального планирования и землеустройства. На основе проведенного исследования автором составлена характеристика Болгарии, произведен анализ современных проблем при ведении землеустройства в стране, а также сформированы предложения по устранению существующих проблем в системе землеустройства Болгарии.

Ключевые слова: землеустройство, земельные ресурсы, правовые нормы, климатические особенности

\section{LAND MANAGEMENT IN BULGARIA}

\section{Elizaveta V. Gninenko}

Moscow State University of Geodesy and Cartography, 4, Gorokhovsky Lane, Moscow, 105064, Russia, Student, phone: (915)101-00-62, e-mail: lebensladge11@gmail.com

\section{Alexander P. Sizov}

Moscow State University of Geodesy and Cartography, 4, Gorokhovsky Lane, Moscow, 105064, Russia, D. Sc., Head of the Department of Cadastre and Foundations of Land Law, phone: (906)716-27-10, e-mail: ap_sizov@mail.ru

This article examines the land management system in Bulgaria, climate features and terrain of the country, minerals, flora, economy, land resources and legal norms of land management, Analogs of Russian documents of territorial planning and land management. Based on the research, the author has compiled a description of Bulgaria, analyzed the current problems in land management in the country, and formed proposals to eliminate existing problems in the land management system in Bulgaria.

Keywords: land management, land resources, legal norms, climate features

\section{Введение}

Целью данного исследования является изучение системы землеустройства и кадастра в Болгарии, анализ современных проблем при ведении землеустройства в выбранной стране, а также формирование предложений по устранению существующих проблем. 
Задачи исследования:

1) Изучить объект исследования - территорию Болгарии;

2) Составить общую характеристику Болгарии;

3) Рассмотреть земельные ресурсы Болгарии и их использование;

4) Изучить правовые основы использования и управления земельными ресурсами в Болгарии;

5) Произвести сравнительный анализ землеустроительной документации и документов территориального планирования в Болгарии и в России;

6) Выявить проблемы и перспективы использования и управления земельными ресурсами.

Объектом исследования является Болгария. Предметом исследования в исследовании выступает система землеустройства и кадастра в Болгарии. Методы исследования - метод системного анализа.

\section{Общая характеристика Болгарии}

Болгария относительно невелика по площади (111 тыс. кв.км), расположена на юге Европы, на северо-востоке Балканского полуострова; омывается водами Черного моря. С 1946 по 1990 год называлась Народная Республика Болгария. Имеет общую границу с пятью странами (Румыния, Турция, Греция, Сербия, Республика Македония). Государственный язык - болгарский, который настолько близок к русскому, что у русскоговорящих туристов не возникает языкового барьера. Персонал на курортах, в отелях и ресторанах, как правило, говорит на русском, английском, немецком и французском языках.

Население Болгарии составляет около 9 миллионов человек, из них $85 \%$ болгары, 9,7\% турки и 5\% цыгане. Население Болгарии за последние 20 лет сократилось почти на миллион человек. Болгарские специалисты называют несколько причин, из-за которых наметилась столь неприятная тенденция: падение рождаемости, а также высокий уровень эмиграции. По некоторым прогнозам, если существующая демографическая ситуация не изменится, то через несколько десятилетий население Болгарии может сократиться на одну треть. Сокращение населения отмечается во многих европейских странах, но в Болгарии этот процесс усугубляется крайне невысоким уровнем жизни.

\section{Климат и рельеф}

На большей части территории Болгарии умеренно-континентальный климат с четко выраженными четырьмя сезонами. На черноморском побережье и в южных районах климат близок к средиземноморскому. В стране средняя температура самого холодного месяца - января - составляет от -2 до +2 градусов по Цельсию. В горах столбик термометра может опуститься до -10 - 15 градусов. Климат Болгарии благоприятен для отдыха, особенно для жителей средней полосы. 
Рельеф Болгарии неоднороден. На относительно небольшой территории страны находятся низменности, равнины, холмы, низкие и высокие горы, большое количество долин и глубоких ущелий. Главной особенностью топографии Болгарии является чередование полос высокого и низкого ландшафта, которые проходят с востока на запад через всю страну. Эти полосы (называемые геоморфологическими областями) с севера на юг носят названия: Нижнедунайская низменность, Стара-Планина, Верхнефракийская низменность и Рила-Родопский горный массив. В Болгарии 3 горных системы: Пирин, Рила и Родопы. Самые восточные области у Чёрного моря холмистые, они постепенно набирают высоту к западу, а крайняя западная часть страны высокогорная. Более двух третей страны - равнины, плато или холмистые земли высотой менее 600 м. Равнины (ниже 200 м) составляют $31 \%$ территории, плато и холмы (200-600 м) - 41\%, низкие горы (600-1000 м) $10 \%$, средние горы (1000-1500 м) $10 \%$, и высокие горы (более 1500 м) $3 \%$. Средняя высота Болгарии - 470 м. Значительная часть территории Болгарии подвержена землетрясениям.

\section{Полезные ископаемые Болгарии}

Болгария не богата запасами полезных ископаемых, и их добыча и переработка занимают незначительное место в экономике страны. Главный вид минерального топлива в Болгарии - это уголь, поэтому небольшие месторождения нефти не могут заменить его. Лигниты (бурый уголь) составляют $92 \%$ всех угольных запасов, которые оцениваются в 5-10 млрд.тонн. Основные месторождения и бассейны, в которых происходит разработака и добыча - ВосточноМарицкий и Западно-Марицкий, а также Софийская область. Поскольку страна бедна топливно-энергетическими ресурсами, она вынуждена широко импортировать нефть, газ и уголь.

Урановая руда добывается в Софийской области и в Средна-Гора. Общие запасы железной руды страны оцениваются лишь в 10 млн. т. Существует несколько месторождений железной руды с примесями марганца, хрома, молибдена. Народнохозяйственное значение имеют также месторождения свинца, цинка и меди. В горах Стара-Планина обнаружены небольшие запасы золота. Вольфрамовая и висмутовая руда добывается в Родопах. В Болгарии насчитывается более 600 природных минеральных источников, имеющих целебные свойства с температурой воды от 8 до 100o.

Высокое плодородие почв определяется тем, что в пределах Нижнедунайской равнины, развиты черноземы, которые имеют пористую структуру, тонкую текстуру, высокую влагоёмкость и содержат большое количество гумуса. Коричневые почвы преобладают в долине Марицы, а в горах распространены серые подзолистые и горно-луговые почвы. В поймах рек и приморских районах - аллювиальные почвы. В последнее время отмечено снижение естественного плодородия почв из-за почвенной эрозии и чрезмерного применения органических и минеральных удобрений. 


\section{Растительный мир Болгарии}

Около 30\% площади Болгарии занято лесами (главным образом бук и дуб, в Рила-Родопских горах - хвойные). В конце XX века в Болгарии леса занимали 3,8 млн. га, или около $30 \%$ площади страны. Из них примерно $31 \%$ - хвойные, а остальные - лиственные с преобладанием бука, дуба, ясеня и граба. Всего $15 \%$ лесных насаждений имеют промышленное значение, а остальные - преимущественно низкопродуктивные либо выполняют водоохранную и почвозащитную функции.

Леса Болгарии представлены дубами на равнинах и хвойными деревьями в горах. Гордость страны - цветы. На первом месте по популярности - конечно же, розы. Без них невозможно представить себе болгарский пейзаж. Кроме того, разведение и продажа роз, а также изготовляемых из этих цветов продуктов, является основным источником дохода для жителей болгарских деревень. Всему миру знакомы сорта болгарского табака. Распространена здесь сирень - кустарник или невысокое дерево из семейства маслиновых.

\section{Экономика}

Болгария - индустриально-аграрная страна. Наиболее развиты машиностроение, черная и цветная металлургия, также пищевая промышленность (табачная, плодоконсервная). Химическая, нефтехимическая и деревообрабатывающая промышленность. В сельском хозяйстве преобладает растениеводство, производство зерна и зернобобовых, табака, овощей, фруктов, винограда, эфирномасличных культур. Мясошерстное животноводство (крупный рогатый скот, овцы, свиньи), рыболовство. Иностранный туризм. Курорты международного значения: Золотые Пески, Албена, Солнечный Берег, Созополь.

\section{Земельные ресурсы Болгарии}

Земельные ресурсы Болгарии представляют собой следующую картину (рисунок):

- пахотная земля - $43 \%$

- постоянные зерновые культуры - $2 \%$

- пастбища $-14 \%$

- леса - $38 \%$

- другое $-3 \%$

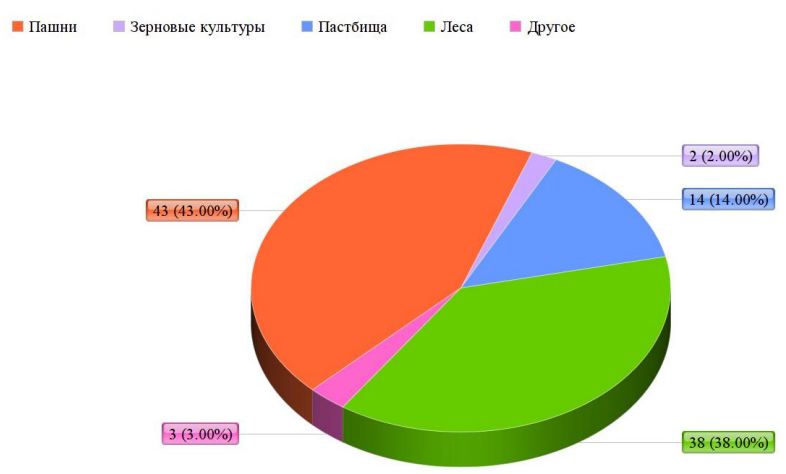

Земельные ресурсы Болгарии 
В Болгарии, Италии, Словении, Венгрии, Сербии и Греции были проведены исследования культурного наследия некоторых поселений под названием SY_CULTour, в основу которых легли идентификация объектов наследия, обоснование связи его с ключевыми заинтересованными сторонами и другими сферами деятельности, использование объекта надлежащим образом и, наконец, использование нового сервиса пользователям. Важность конкретной культурной ценности для развития территории определяется потенциалами экономического, экологического, социального и культурного развития.

Освоение склоновых земель и предгорий под промышленные сады и виноградники отвечает требованиям рационального использования земельных и природных ресурсов, интенсификации и эффективности сельскохозяйственного производства, осуществлению продовольственной независимости страны (таблица). Обеспечение продовольственной независимости нашей страны является не только политической, но и социально-экономической задачей, способствующей оздоровлению нации. Удельный вес садов и виноградников на склоновых землях в таких странах как Австрия, Болгария, Венгрия, Испания, Италия составляет 30-50\% и более. Следует также отметить и то, что в суровые зимы сады в горах не вымерзают вследствие температурной инверсии; в горах выпадает больше осадков, что не уступает равнинным условиям. Хотя горные сады вступают в плодоношение на 2-3 года позже равнинных, но продолжительность жизни плодовых деревьев в горных условиях больше. Сады, размещенные на оптимальных высотах, дают более качественные плоды, чем на равнине, так как в горах более высокая интенсивность освещения, благоприятный радиационный режим, воздушный дренаж.

Важным вопросов при организации использования этих земель является определения их пригодности под промышленные сады и виноградники и подбор соответствующего сортового состава насаждений. При определении пригодности первостепенное значение имеет учет рельефа, расчлененности территории, почвогрунтов.

Урожай зерновых и вносимые дозы минеральных удобрений в некоторых странах Европы. [6]

\begin{tabular}{|c|c|c|c|c|}
\hline \multirow[t]{2}{*}{ Страны } & \multicolumn{3}{|c|}{$\begin{array}{l}\text { Средиие дозы минеральных удобрений, } \\
\text { кr/га (д.в.) }\end{array}$} & \multirow[t]{2}{*}{$\begin{array}{l}\text { Средиий урожай } \\
\text { зерновых u/ra }\end{array}$} \\
\hline & $\mathbf{N}$ & $P$ & K & \\
\hline Австрия & 79,3 & 38,1 & 44,5 & 54,0 \\
\hline Болгария & 31,6 & 2,7 & 4,2 & 19,6 \\
\hline Венгрия & 66,7 & 15,3 & 12,8 & 40,2 \\
\hline Германия & 148,5 & 35,1 & 56,6 & 62,8 \\
\hline Россия & 8,4 & 2,6 & 3,1 & 13,0 \\
\hline Румыния & 28,9 & 15,1 & 1,8 & 24,3 \\
\hline Украина $_{\text {к }}$ & 18,4 & 3,6 & 5,3 & 20,1 \\
\hline Франция & 138,1 & 57,5 & 81,4 & 70,8 \\
\hline Чехия & 84,6 & 16,3 & 17,8 & 41,9 \\
\hline
\end{tabular}


В настоящее время консолидация земель проводится во многих странах в достаточно большом объеме. Это, прежде всего, страны Северной Европы (Швеция, Финляндия, Норвегия), Польша (южные районы), Румыния, Болгария и др. Работы осуществляются на основе специальных землеустроительных проектов по консолидации земель. Их разрабатывают государственные или частные компании, имеющие соответствующие лицензии на эти землеустроительные действия.

Профессиональные кадры для развития системы землеустройства и кадастра в Болгарии готовит Университет архитектуры, строительства и геодезии (г. София).

\section{Правовые основы использования и управления земельными ресурсами}

Земля в Болгарии - это перспективный вариант капиталовложения в недвижимость. Купить земельный участок под застройку - перспективный вариант грамотного вложения средств. Обычно владельцы - физические лица, в том числе и иностранцы, а также фирмы, планирующие использовать покупку для последующего строительства коттеджного посёлка или комплекса апартаментов с квартирами с целью сдачи в аренду. Болгарское законодательство очень лояльно к таким инвесторам, в том числе и в пределах территории приморских городов и непосредственно у моря.

Продаются в основном наделы от частных лиц. Муниципалитеты продажу участков на побережье практически не инициируют. Есть возможность подобрать недвижимость под строительство дома или коммерческого объекта как на берегу моря, так и в зоне горнолыжного или СПА-курорта. Стоимость отвечает рыночным условиям. Покупают подобные объекты люди с желанием вложить капитал. Стране и ее властям интересно предлагать участки под застройку недорого, так как даже при любых негативных тенденциях в экономике иностранные инвестиции смогут удержать ее на плаву.

Статья 2 Закона Болгарии от 12 марта 1999 г. № 23 «О подземных природных ресурсах» относит к подземным природным ресурсам минералы - природные подземные ресурсы; минеральные природные ресурсы - промышленные материалы; нефть и газ; твердое топливо; строительные материалы; материалы скального происхождения; драгоценные и полудрагоценные камни; промышленные технологические отходы от горного производства и переработки полезных ископаемых, которые не являются собственностью граждан и юридических лиц.

Природные подземные ресурсы являются исключительной государственной собственностью (ст. 3(1) Закона). К природным подземным ресурсам строительным материалам относятся ресурсы, использующиеся для целей строительства населением и добытые в объеме, не превышающем 10000 куб. м в год.

Согласно ст. 5 Закона правами на природные ресурсы являются разрешение и концессия. Регистрация открытия подземного природного ресурса в регистре открытий месторождений не меняет право собственности, цель и исполь- 
зование недвижимого имущества на поверхности земли. Выданные разрешения на геологическое изучение или добычу полезных ископаемых или концессии на добычу полезных ископаемых дают право их обладателям достичь соглашений с владельцами прав на поверхность земли, с тем чтобы избежать препятствий и затруднений в их деятельности.

Владелец разрешения или концессии и собственник земли могут заключить контракт, в котором будут предусмотрены права владельца разрешения или концессии по использованию земли на период действия разрешения или концессии и определены условия компенсации за использование земли. Если соглашение не было достигнуто, то владелец разрешения или концессии может обратиться с заявлением в соответствующие органы власти с просьбой экспроприации частного недвижимого имущества или его части при условии получения предварительной компенсации (ст. 75 Закона).

В Болгарии есть общедоступные источники информации, где можно узнать цены на недвижимость. Индекс рынка торговли недвижимостью (ИРТН), который позволяет получать информацию о ценах на индивидуальные жилые дома и квартиры в многоквартирных домах, рассчитывается Национальной ассоциацией компаний по торговле недвижимостью. Однако этот индекс не лишен некоторых недостатков, поскольку он рассчитывается лишь на ежеквартальной основе. Он является чрезмерно общим и не позволяет проводить сопоставление цен на недвижимость по ее типу или местоположению.

\section{Аналоги российских документов территориального планирования и землеустройства}

В Болгарии разрабатываются проекты землеустройства, связанные с созданием системы противоэрозионных мероприятий, террасированием или консервацией земель на основе инженерных расчетов смыва почв.

Так же, как и в России, используются кадастровые карты. Однако кадастровой информацией охвачены лишь 70-75\% территории Болгарии, и в этой области всё ещё ведутся работы.

Вся территория Болгарии охвачена новой геодезической системой, которая называется Болгарской системой геодезических измерений. В ее основу положены принципы функционирования Европейской земной референцной системы (ЕЗРС). Болгарская система геодезических измерений включает в себя основные геодезические параметры, а именно систему геодезических координат, систему высот и картографическую проекцию.

\section{Заключение}

В ходе изучения системы землеустройства в Болгарии, были выделены основные проблемы, на которые следует обратить особое внимание. По итогам исследования, сформулирован ряд рекомендаций по совершенствованию системы землеустройства Болгарии: 
1) Необходимо усилить сотрудничество и координацию между органами власти, занимающимися вопросами управления земельными ресурсами; прежде всего, это касается четкого разделения основных обязанностей (в условиях, когда каждое агентство отчитывается перед одним отраслевым министерством) в сочетании с обеспечением в достаточном количестве человеческими и финансовыми ресурсами. Ответственность за управление земельными ресурсами (включая укрупнение земельных участков) целесообразно возложить только на один государственный орган.

2) Во избежание ошибок в картах земель сельскохозяйственного назначения, на которые восстановлены права собственности, следует укреплять сотрудничество между министерствами сельского и лесного хозяйства и регионального развития и общественных работ. Эти действия будут способствовать повышению точности кадастровых карт в будущем.

3) Для предотвращения неоправданных капиталовложений в сельскохозяйственные земли (и спекуляций ими) необходимо перейти на применение методов планирования, а также принять дополнительные нормативно-правовые акты. Следует в обязательном порядке установить налог на сельскохозяйственные земли, а существующие исключения в связи с налогообложением земель должны быть отменены.

4) В Болгарии отсутствует стратегия в области землеустройства, предусматривающая перепрофилирование фермерских хозяйств. Сельхозпроизводители могут расширять свои земельные владения путем аренды или покупки земли. Рынок аренды является нетранспарентным, а добровольные инициативы по укрупнению земельных участков не могут позволить решить проблему структурного дефицита, связанного с размерами фермерских хозяйств. Ставки арендной платы чрезмерно высоки и экономически невыгодны. По-прежнему отсутствуют реальные стимулы, поощряющие аренду земли. В качестве наиболее важного долгосрочного решения проблемы рассматривается законодательное регулирование укрупнения земельных участков, которое включает в себя создание правовых инструментов для проведения мероприятий как обязательного, так и добровольного характера по укрупнению земельных участков. Кроме того, в законодательстве следует отразить опыт моделей государственно-частного партнерства, которые нашли применение в пилотных проектах. Следует укреплять международное сотрудничество в области общих процессов укрупнения земельных участков и повышения качества жизни в сельских районах.

5) В практике землеустроительной работы в связи с использованием Государственного земельного фонда необходимо руководствоваться видением стратегических перспектив, которые должны быть направлены на реализацию долгосрочных задач развития сельских районов.

6) Отсутствие начального капитала, судя по всему, является серьезным препятствием для потенциальных предпринимателей в сельских районах. Следует принять схемы выдачи первоначальных микрокредитов, способствующих доступу к кредитованию мелких сельскохозяйственных предприятий. Поскольку коммерческие банки, судя по всему, не являются надлежащими партнерами 
нетоварных хозяйств в плане кредитования, одним из вариантов могло бы явиться принятие используемого в Германии подхода к микрофинансированию.

7) Крайне важное значение для дальнейшего совершенствования системы контроля качества в различных областях землеустройства имеет подготовка экспертов и государственных служащих, а также проведение кампаний по повышению информированности. Кроме того, имеющуюся информацию также следует распространять через средства массовой информации и на всех уровнях системы образования.

\section{БИБЛИОГРАФИЧЕСКИЙ СПИСОК}

1. Официальный сайт Министерства сельского хозяйства и продовольствия Болгарии: https://www.mzh.government.bg/bg/.

2. Конституция Болгарии от 13 июля 1991 г.

3. Федеральный закон Болгарии от 12 марта 1999 г. № 23 «О подземных природных ресурсах».

4. Географический портал о странах мира. Болгария.

5. https://geo-1.ru/bolgariya-informatsiya-o-strane-dostoprimechatelnosti-istoriya/.

6. Доклад ООН о современных проблемах землеустройства зарубежных стран.

(C) Е. В. Гниненко, А. П. Сизов, 2021 